Citation: Popek-Bernat, K. (2017). The PLUS-MINUS axiological parameter in selected sex-related orientational metaphors in Spanish and its role in interlingual contrastive studies. Cognitive Studies / Études cognitives, 2017(17). https://doi.org/10.11649/cs.1318

\title{
THE PLUS-MINUS AXIOLOGICAL PARAMETER IN SELECTED SEX-RELATED ORIENTATIONAL METAPHORS IN SPANISH AND ITS ROLE IN INTERLINGUAL CONTRASTIVE STUDIES
}

\begin{abstract}
The purpose of this article is to verify the functioning of the PLUS-MINUS axiological parameter in the orientational sexual metaphors which exist in Peninsular Spanish. The initial premise of the investigation is based on the concept proposed by Tomasz P. Krzeszowski (1993), according to which, upon studying image schemas, an additional parameter called PLUS-MINUS should be taken into account. This parameter is considered by Krzeszowski as "directly responsible for the dynamism of the metaphorization processes inherent in the formation of concepts based on the relevant schemata. Among [them are] the concepts of varying degrees of abstraction and of varying degrees of axiological load". The present paper aims to demonstrate that the inclusion of the PLUS-MINUS parameter is necessary for the correct reconstruction of the picture of particular elements of reality grounded in language. An attempt will be made to try to answer the question of whether the type of orientation is in fact associated with a particular axiological load universally, or whether the axiology connected with the spatial orientation may vary within a single system or two different language systems. In this respect, the final part of the paper will encompass some examples of linguistic manifestations of sex-related orientational metaphors in Spanish with their Polish counterparts.

Keywords: PLUS-MINUS axiological parameter; orientational metaphors; Spanish erotic lexicon; image schemas; contrastive linguistics
\end{abstract}

\section{Metaphorical orientations and the concept of embodied me- aning}

Lakoff and Johnson, in one of their works which gave birth to the Cognitive Theory of Metaphor, claim that "metaphorical orientations are not arbitrary. They have a basis in our physical and 
The PLUS-MINUS axiological parameter in selected sex-related orientational metaphors in Spanish...

cultural experience." According to them, "these spatial orientations arise from the fact that we have bodies of the sort we have and they function as they do in our physical environment." (Lakoff \& Johnson, 1980, p. 14).

Following these lines of reasoning, in their later research the American academics state that:

"Real people have embodied minds whose conceptual systems arise from, are shaped by, and are given meaning through living human bodies. The neural structures of our brains produce conceptual systems and linguistic structures that cannot be adequately accounted for by formal systems that only manipulate symbols." (Johnson \& Lakoff, 1999, p. 6).

These observations refer clearly to the concept of embodied meaning ${ }^{1}$, developed, among others, by both Lakoff and Johnson themselves in their previously mentioned investigations and by Johnson individually (Johnson, 1987, 2007). This concept assumes that the way in which humans understand reality is a reflection of their sensorimotor activity in the outside world, which takes the form of constantly repetitive actions. These actions lead to the emergence of preconceptual structures, called image schemas or image schemata (Johnson, 1987, p. 28; Lakoff, 1987, p. 267). They give rise to conceptual structures which are reflected in the language we use (Lakoff, 1987, p. 267).

According to Johnson, image schemas organize our experiences and help us to comprehend them. They are "patterns [which] emerge as meaningful structures for us chiefly at the level of our bodily movement through space, our manipulation of objects, and our perceptual interactions." (Johnson, 1987). On one hand, preconceptual image schemata directly structure concrete, non-abstract concepts. On the other hand, they shape abstract concepts through metaphorical mappings of the structure of the schemata from the source domain into the target domain, (Johnson, 1987, p. 169).

\section{The PLUS-MINUS axiological parameter in preconceptual image schemata}

In 1993 Tomasz P. Krzeszowski proposed the inclusion of an additional parameter, which he called PLUS-MINUS, in the study of preconceptual image schemata. The researcher considers that:

"[This parameter is] directly responsible for the dynamism of the metaphorization processes inherent in the formation of concepts based on the relevant schemata. Among these concepts are the abstract concepts [...] as well as other concepts of varying degrees of abstraction and of varying degrees of axiological load" (Krzeszowski, 1993, p. 310).

It would appear that some concepts are related to positive or negative values in a permanent and immutable way regardless of the context. However, there are situations when the axiology connected with one concept depends on the type of schema evoked by a specific linguistic expression.

\section{The (dis)ambiguous axiology of the concept of COPULA- TION and the aims of the study}

One of the conclusions drawn by Krzeszowski is that there exists a stable axiology associated with the act of copulation which, according to him, is a highly positively loaded concept. He points out that copulation may be interpreted as an interpersonal bond, the aim of which is the transmission of life. Thus, it belongs in the LINK schema, or as unity in the PART-WHOLE

\footnotetext{
${ }^{1}$ In order to maintain the typographic cohesion of this paper, the newly introduced terms which refer to the contributions of other authors appear in italics. When they are used more than once the type of font is standard.
} 
The PLUS-MINUS axiological parameter in selected sex-related orientational metaphors in Spanish...

schema. Consequently, it combines the positive values of both schemata from which it arises (Krzeszowski, 1993, p. 313).

It is interesting to collate the conclusions drawn by Krzeszowski with the results of the current author's own research on Spanish erotic lexicon, according to which copulation and related concepts are axiologically ambiguous and not so straightforward ( $c f$. Popek-Bernat, 2015). Taking this into account, and following the premises developed by Krzeszowski, this paper intends to establish whether and to what extent the type of orientation related to a particular image schemata, which is manifested in language by means of specific expressions, determine the axiology of the concept of our interest (in this case, the act of copulation). In order to answer these questions, the axiology grounded in some orientational sex-related metaphors detected in Spanish will be analyzed and reconstructed, applying the PLUS-MINUS parameter. Afterwards, an attempt will be made to determine whether the type of orientation is in fact associated with a particular axiological load universally, or whether the axiology connected with the spatial orientation may vary within a single system or two different language systems. In the final part of the paper, some examples of the linguistic realizations of sex-related orientational metaphors in Spanish will be compared with their Polish counterparts.

\subsection{The PLUS-MINUS axiological parameter in selected orientational schemata}

Before analyzing specific examples, it is necessary to outline some general remarks concerning the function of the PLUS-MINUS parameter in selected orientational image schemata ( $c f$. Krzeszowski, 1993, pp. 320-323).

\subsubsection{The UP-DOWN orientation}

This schema refers to the canonical form of the human body, directed upwards. Human physical development is connected with growing upwards, which is one of the basic positive experiences, supported by many other socio-cultural habits and situations (Krzeszowski, 1993, p. 321). It is common in many societies to move the thumbs up to signal that everything is fine. Our bodies are erected and our heads lifted up when we feel well and comfortable. When we smile, the corners of our mouths curve upward. The UP orientation is therefore positively charged (pp. 321-322). It is reflected in many languages. In English, for example, there exist expressions like he has risen to the top or you've grown in my eyes. ${ }^{2}$

According to Krzeszowski, the DOWN orientation is associated, in contrast, with negative values. When we want to indicate that something has failed or gone wrong, we normally direct our thumbs downwards. When we experience a decrease in happiness or feel depressive, the corners of our mouths curve down (pp. 321-322). In English, this is linguistically illustrated by such expressions as he fell into depression or he came down with flu.

\subsubsection{The FRONT-BACK orientation}

This orientational schema is supported by the UP-DOWN schema. As observed by Krzeszowski:

Due to the evolutionary process [...] man assumed the erect position as a result of which what was originally FRONT (the head) became also UP without actually ceasing to be FRONT (human face). Similarly, what was BACK became DOWN without ceasing to be BACK. (Krzeszowski, 1993, p. 322).

These resemblances are visible at the level of axiology because the values associated with the FRONT-BACK orientation are the same as in the case of the UP-DOWN orientation. FRONT, allied to UP, "has a definitely positive value due to the fact that the fundamental experience

\footnotetext{
${ }^{2}$ All the examples of orientational schematas are quotations of Krzeszowski's ideas (1993, pp. 320-326).
} 
connected with this orientation is the experience of human face, the most representative part of the human body" (Krzeszowski, 1993, p. 322). BACK, by contrast, is conventionally a negatively loaded orientation. "The back parts of our bodies are certainly less representative of us as human beings." (Krzeszowski, 1993, p. 323).

The positive values attributed to FRONT and the negative ones attributed to BACK are illustrated in most languages by numerous expressions. In English, for example, when somebody is sick and helpless, this person is on one's back. If somebody wants to have good seats in the theatre or another type of auditorium, they should reserve the front ones.

\subsubsection{The IN(TO)-OUT orientation}

The IN(TO)-OUT schema is not ascribed by Krzeszowski to the category of orientational image schemata $^{3}$, although it is obviously connected with a concrete type of preconceptual orientation of particular human experiences. He alludes to the IN(TO)-OUT orientation when he describes the CONTAINER schema and its two variants: BODY-AS-A-CONTAINER and BODY-IN-ACONTAINER. The axiologies linked to these variants are similar only to a certain degree, mainly due to the fact that their motivations are different (Krzeszowski, 1993, pp. 314-317).

The BODY-AS-A-CONTAINER variant is grounded in the experiences of breathing and eating. What we usually introduce to the BODY-AS-A-CONTAINER are different sorts of substances indispensable for the functioning of our organisms, without which it would be impossible to survive (e.g. nutrients or inhaled air). At the same time, our organisms expulse, exhale or excrete OUT everything which is, or may be, harmful or unnecessary. Consequently, IN(TO) is conventionally associated with positive values and OUT with negative ones (Krzeszowski, 1993, p. 315).

Nevertheless, Krzeszowski proves that the axiology attributed to the IN(TO)-OUT orientation is not stable. As far as the second variant of the CONTAINER schema is concerned, the axiological load of the two poles of this orientation is constantly changing. Since "the primary experience associated with [this variant of] the CONTAINER schema is that of being in our mother's womb" (Krzeszowski, 1993, p. 315), IN(TO) is positively charged, as the container (mother's womb) provides favorable conditions for the development of the organism inside and protects it from external factors. On the other hand, the body in a container is in some way limited by its boundaries and sooner or later it has to get OUT in order to be able continue its further development outside. In this case, the $\mathrm{IN}(\mathrm{TO})$ orientation is associated with negative values because it involves the limitation of freedom and constrictions. Getting out of the container or, more precisely, freeing the body from it, is in this context synonymous to gaining freedom, which is, almost universally, positive. In other words, this interpretation evokes a negative axiological charge attributed to the IN(TO) orientation (Krzeszowski, 1993, p. 316).

It must be remembered, however, that getting out of a mother's womb leads not only to freedom, but also exposes us to potential dangers or threats. There is no exterior "shell" to protect us. Because of this, the OUT orientation in the context of the BODY-IN-A-CONTAINER schema is axiologically as complex and contradictory as the IN(TO) orientation. It may be charged positively (the body imprisoned in the container, which succeeds in getting out of it, gains freedom) or negatively (the body which comes out of the container is not safe anymore as it loses its natural protection) (Krzeszowski, 1993, pp. 316-317).

The "axiological dialectics" (Krzeszowski, 1993, p. 315) described above is deeply grounded in language structures. To give some examples, pairs of expressions like in business - out of business, within reach - out of reach, the Democrats are in - the Republicans are out reflect the contradictory values stemming from the IN orientation (conventionally positively loaded) and the OUT orientation (conventionally negatively loaded). Nevertheless, observed by Krzeszowski,

\footnotetext{
${ }^{3}$ In his article Krzeszowski singles out 3 types of orientational schemata: UP-DOWN, FRONT-BACK and RIGHT-LEFT (Krzeszowski, 1993, pp. 320-325). The last one is not described within this paper since the study of Spanish sex-related lexicon, which constitutes a point of departure for the present work, did not reveal its presence in the erotic context.
} 
[...] the assignment of values [to a particular orientation] may depend on a number of factors, such as other schemata which may interact with the CONTAINER schema as well as the value of the container itself; if the container, for example, home, is positively charged, being IN it is also positively charged; if the container, for example, prison, is negatively charged, being IN it is also negatively charged. (Krzeszowski, 1993, p. 317).

\subsubsection{Correlations between orientational schemata and other types of schemas}

The CONTAINER schema, referred to in the context of the IN(TO)-OUT orientation, is also related to the UP-DOWN orientation. As Krzeszowski states: "through our mouths, situated in the upper parts of our bodies, we take in nourishment, which sustains our life" (Krzeszowski, 1993, p. 321). This preconceptual experience reinforces, therefore, a positive axiology of the UP orientation.

As far as the IN(TO)-OUT orientation is concerned, it evokes not only the CONTAINER schema, but also the LINK schema, which, for its part, overlaps with the BODY-IN-A-CONTAINER variant of the CONTAINER schemata. Krzeszowski claims that:

When we are born, we get OUT of the original CONTAINER, and at the same time the umbilical cord, our first LINK, is broken. In this way, both getting out of our mother's womb and severing the umbilical cord constitute primary experiences of acquiring freedom. [...] However, the LINK is only physically broken. On the social level, it continues to exist as we still very much depend on our parents for both food and protection within the bounds of the family, which we begin to conceive metaphorically as a SHELTER. [...] Later in life, we form new links and enter new containers [...], our freedom is constrained by new links and new containers. Thus, the dialectical struggle grounded in this primary axiological experience continues within us: on one hand, we wish to be free, and we consider freedom to be among the most outstanding positive values, while, on the other, hand, we willingly impose constraints on our freedom to obtain security and protection. (Krzeszowski, 1993, p. 316).

The FRONT-BACK schema, described in subsection 2.1.1, is correlated with other schemata, as is the case with other orientational schemata.

The FRONT-BACK schema, reinforced by the UP-DOWN one, is additionally motivated by the BALANCE and SOURCE-PATH-GOAL schemata. The loss of equilibrium normally causes a fall (DOWNside movement), prevents us from moving towards the FRONT, and stops us from reaching a chosen GOAL. When we manage to keep our balance, we maintain an erected body position, directed UPwards, we are able to move forward in a chosen path, gradually reaching our GOAL. These experiences are associated with a concrete type of axiological load (positive or negative), resulting from the functioning of the PLUS-MINUS parameter within a particular schema. Both UP and FRONT, as well as BALANCE and GOAL, are positively charged. Their axiologically negative counterparts are DOWN, BACK, LACK OF BALANCE and stillness which makes it impossible to reach the GOAL (Krzeszowski, 1993, pp. 321-322).

\section{Orientational metaphors in Spanish erotic lexicon}

Spanish erotic lexicon abounds in expressions which are linguistic realizations of different types of orientational metaphors related to heterosexual intercourse. This conclusion was drawn from the analysis of 98 lexical units which elaborate these metaphors and are registered in Diccionario del sexo y el erotismo by Félix Rodríguez González (2011). ${ }^{4}$ All of the 98 lexical units designate the act of copulation between people of different sexes, or are semantically related to activities aimed at triggering sexual excitation.

\footnotetext{
${ }^{4}$ The most recent (2011) and expanded (more than 6.000 entries) lexicographic repertoire of Spanish sex and erotic-related terminology.
} 
The UP-DOWN, IN(TO)-OUT and FRONT-BACK orientations evoked by the sex-related metaphors in question are associated with the type of movement denoted by their different elaborations. In addition to this, however, they are associated with a specific projection of male and female genitalia which are linguistically positioned in a specific location in relation to different parts of the body of the agent or patient of sexual action. Taking into account the basic (nonerotic) meanings of the lexical items which form the basis of the metaphors of those orientations, they can be categorized into the following groups:

1. Expressions which semantically allude to the act of changing vertical position in space by moving UPwards, e.g. montar ('to go up, to climb'), empinarse ('to stand on one's toes or, referring to the horse or other quadrupedal animal, to rear up' $)^{5}$;

2. Expressions which semantically allude to the act of changing vertical position in space by moving DOWNwards, e.g. apearse, descabalgar ('to dismount the horse'), enterrar [la sardina] ('to bury, to dig [the sardine] in the ground'), acostarse ('to lie down, to change the body position from the vertical to the horizontal one');

3. Expressions which semantically allude to the act of changing horizontal position in space by moving something INwards, e.g. meter ('introduce something into an object or a container'), entrar ('to enter, go in');

4. Expressions which semantically allude to the act of changing horizontal position in space by moving something OUTwards, e.g. soltar el manda( $d) o$ ('to free, to let the phallus out'), echar un cohete ("to launch a rocket, to throw a banger");

5. Expressions which are not semantically related to any explicitly directed movement but evoke the FRONT-BACK orientation through reference to a concrete part (front or back) of the human body, e.g. culear ('to move the bottom'), rabear ('to wag the tail').

\section{Axiological analysis of selected sex-related orientational metaphors in Spanish}

\subsection{The sexual act is an UPward movement}

This orienational metaphor is evoked in Spanish mainly by means of expressions which, in a nonerotic context, are semantically connected with mounting and riding a horse. Most of them are based on the verb montar (see Table 1) and its basic meanings are: 'to go up, to climb', 'to get on (a horse)' or 'to ride (a horse)' (DRAE). ${ }^{6}$ It is necessary to emphasize that within the semantic scope of Spanish verbs and phrasal verbs which designate the activity of riding a horse (cabalgar / montar a caballo) the action of climbing or going up is always being denoted (literally designated in Spanish by the verb subir). All this taken into account, it becomes clear that the lexical items formed on the basis of the verb montar on all occasions entail the UPward movement.

According to the previously quoted observations by Krzeszowski, whatever is currently UP or is directing UPwards shall be associated with positive values. It is interesting to contemplate these conclusions in the context of the expressions included in Table 1 (p. 7). Most Spanish expressions which designate heterosexual intercourse, based on the verb montar, evoke a male grammatical subject. It tends to be a man who "mounts a woman" in erotic situations. The high frequency of the use of the expressions number 2 and 3 in Spanish reflect this. As a matter of fact, a woman

\footnotetext{
${ }^{5}$ The meanings of Spanish expressions are literal translations of their lexicographis definitions registered in general Spanish dictionaries. It needs to be stressed that some of the quoted examples evoke different orientations and, consequently, elaborate different orientational metaphors in Spanish and English.

${ }^{6}$ The abreviation DRAE refer to the 22nd edition of Diccionario de la lengua española by Real Academia Española (online version, http://www.rae.es/).
} 
The PLUS-MINUS axiological parameter in selected sex-related orientational metaphors in Spanish...

Table 1: Selected Spanish erotic expressions with the verb MONTAR and their translations into English $^{7}$

\begin{tabular}{|l|l|}
\hline Spanish expressions & Literal translations to English \\
\hline 1. Montar en barra & 1. To get on / to mount a bar \\
\hline 2. Montar una mujer & 2. To get on / to mount a woman \\
\hline 3. Montarla & 3. To get on / to mount her \\
\hline
\end{tabular}

who participates in a sexual act is often called jaca or yegua (in English mare). In these cases, it is the man who moves UPwards in order to mount her. It is important to note that initially the man is located DOWN and the woman is UP. However, when it comes to the intercourse between them, the positioning of lovers in the vertical axis is inverted. After climbing UP, the man places the woman DOWN and gets on her as if he was a horse rider who mounts a mare. Consequently, what we are dealing with is the projection of a male lover who is directing UPwards, trying to reach his GOAL, gradually reinforcing his position. The action of reaching the GOAL (UP) involves leaving the woman DOWN. The role of the man located UP seems then to be crucial since he has control over the whole situation, and where the mare moves afterwards depends solely on his whim. According to Rodríguez González, the expressions formed on the basis of the verb montar which connote the action of mounting the woman entail also the action of dominating her or even taking possession of her by a man (Rodríguez González, 2011, p. 691). This perspective implies that the woman involved in sexual intercourse receives the attributes both of an animal and of an object which may be possessed. Undoubtedly it significantly lowers her axiological and ontological status since the axiology is determined, among others, by the anthropocentric attitude of man towards the world around him, which contributes to the attribution of negative values to all of the non-human elements of reality (Tokarski, 1991, pp. 75-76).

The positive image of a male horse rider, who is UP, contrasts with the negative image of the female, who is dominated, moved DOWNwards from the upper position, and animalized. The axiology emerging from the metaphors elaborated by the described expressions is therefore consistent with the axiology stemming from the UP-DOWN schemata after the insertion of the PLUS-MINUS parameter to its study. It is additionally reinforced by the axiology of the SOURCEPATH-GOAL schema (a man reaches his GOAL through the realization of the Upward movement, which increases the positive axiological load associated with the male lover).

The UP-DOWN orientation in a sex-related context is, however, not connected with a stable axiology since it involves movement. In the case of expressions which realize the metaphor THE SEXUAL ACT IS AN UPWARD MOVEMENT, the man at first is positioned DOWN (which should be associated with negative values attributed to him) and only later he is UP (which suggests that he is positively charged). In order to determine correctly the axiology emerging from orientational schemata which evoke a movement towards a particular direction, the possible correlations with other schemata (e.g. SOURCE-PATH-GOAL) should be taken into account, along with the orientation of this movement and its final result. Only on this basis is it possible to reconstruct the values attributed to a concrete expression.

Before embarking on the analysis of other orientational metaphors related to sexual intercourse in Spanish, it is worth examining expression number 1 included in Table 1. This expression proves that the verb montar is not always associated with the male grammatical subject. This has an influence on the axiology of the orientational metaphor evoked.

As far as expression number 1 is concerned, a woman is not only a grammatical subject but also the agent of the action of 'getting on / mounting a bar'. Consequently, it is the woman who makes the UPward movement. As a result, during intercourse the woman is the person who is UP and who plays a crucial role in the act. The values attributed to the female lover are highly positive

\footnotetext{
${ }^{7}$ The Spanish expressions included in the Table are presented in alphabetical order.
} 
in this case. The male lover, by contrast, is negatively loaded. This negative axiology of the man is motivated by his position in space (he is situated DOWN, below his female counterpart) and also influenced by the anthropocentric perception of reality (see above). The allusion to the male lover entailed by the expression in question is fairly implicit and hardly noticeable since it is made through metonymical extension. The concept of barra (bar) is to be interpreted as a metaphorical projection of the phallus. In this case, it is more than obvious that it is not only the male sex organ itself on which the woman is trying to get during the sexual act but the entire man. Assuming that the phallus, which is conceived in terms of a bar, stands for the whole person, what we perceive is the reification of the man as a lover (he receives the attributes of a bar) and his axiological depreciation.

\subsection{The sexual act is a DOWNward movement}

According to analysis of Spanish erotic lexicon, the expressions which evoke this orientational metaphor may be divided into 3 groups based on their non- erotic meanings:

1. Expressions semantically connected with horse-riding.

2. Expressions semantically connected with changing body position from vertical to horizontal.

3. Expressions semantically connected with the activity of directing an object DOWNwards, e.g. putting something underneath the ground.

Among the expressions ascribed to group 1 one can find verbs such as descabalgar or apearse which, according to their basic lexicographical definitions registered in DRAE, refer to the action of dismounting a horse. The participant of a heterosexual act, who is initially UP as they mount the other lover, realizes a DOWNward movement, towards the orientation conventionally associated with negative values. It is worth mentioning that the verb descabalgar in an erotic context alludes to the finalization of the intercourse (Rodríguez González, 2011, p. 322), whereas the verb apearse refers to its momentary interruption and tends to be used as part of the expression apearse en marcha (in English 'to alight from the horse in motion'), which is associated with the practice of coitus interruptus (Rodríguez González, 2011, p. 95). Because of this, the DOWNward movement shall be related to the action of ceasing (temporarily or permanently) the intercourse. This means that only the final stage of the sexual act, or its momentary interruption, have a negative axiological charge, rather than the entire sexual act.

As far as the second group of expressions is concerned, it is represented, on one hand, by the lexical items referring in non-erotic context to the action of lying down to bed (e.g. acostarse, empiltrarse, encamarse) and, on the other hand, by the units semantically connected with the action of falling to the ground and rolling around (e.g. revolcarse).

In the case of the former expressions, it is worth investigating whether the DOWNwards orientation evoked by their non-erotic meanings determine a potentially negative axiology of the sexual intercourse. It seems that the lovers projected by means of these verbs are changing their body position from the vertical to the horizontal in order to feel more comfortable. We normally lie down to bed to take a rest or relax. From this perspective, the horizontal position achieved by us as a consequence of the DOWNward movement becomes our GOAL, which improves our comfort. The GOAL, which is conventionally positively loaded, therefore causes a reorientation of conventionally negative axiology attributed to the DOWN orientation and creates a positive axiology of the sexual act illustrated by the orientational metaphor THE SEXUAL ACT IS A DOWNWARD MOVEMENT. It should not be forgotten, however, that changing one's body position from the vertical to the horizontal may be also triggered by a negative experience, e.g. illness. When we are ill, we often lose energy and we do not have enough strength to keep walking or even to remain standing. In other words, illness can cause DOWNward movement. Despite this negative connotation, it is clear that the bed becomes the GOAL of our movement towards DOWN. When 
we are ill and lie down in bed, our state of health normally improves. This experience reinforces the positive axiology associated with the metaphor which evokes the DOWN orientation. These observations show that the DOWN orientation in a sex-related context does not always denote negative values.

Similar conclusions may be drawn from the analysis of the verb revolcarse. As mentioned above, in a non-erotic context it alludes to the action of falling to the ground and rolling around, which means that it evokes an implied animal metaphor. The actions of falling down to the ground and rolling around are typical of many animals (e.g. dogs) when they want to play or to express their joy. Due to this fact, the verb revolcarse is to be associated with a positively grounded experience. However, the image of lovers projected by the metaphor elaborated by means of this expression is not so positive. They roll around on the ground as if they were animals. Even if they experience some positive emotions, from the axiological point of view they receive animal (non-human) attributes. It needs to be remembered that animals are traditionally considered as less valuable than humans, who are situated higher in the hierarchy of the great chain of being (see 4.1). Because of this, the anthropocentric perspective yet again reinforces a negative axiological load of the participants of the intercourse who realize the DOWNward movement. Nevertheless, it does not affect the axiology associated with the intercourse itself since the negative axiological load conventionally attributed to the DOWN orientation is reoriented under the influence of the positive axiology attributed to DOWN interpreted as a GOAL (through the correlation with the SOURCE-PATH-GOAL schema). When one achieves the goal, they will achieve joy.

Despite these observations, the orientational metaphor THE SEXUAL ACT IS A DOWNWARD MOVEMENT remains associated in most cases with the negative axiology typical of the DOWN orientation. It is illustrated, among others, by means of the expression enterrar la sardina, which literally means 'to bury a sardine'. La sardina is one of numerous Spanish lexical items which refer metaphorically to the penis. The action of 'burying', which involves digging down in the ground, evokes the DOWNward movement. A conventionally negative axiology of DOWN is in this case reinforced by the reference to the negative experiences of death and funeral. However, it is interesting that burying the sardine is connected with placing it $\mathrm{IN}$ (side) a hole. This means that DOWN overlaps here with IN, the orientation conventionally associated with positive values. It weakens the intensity of the negative axiological load attributed to SEXUAL ACT evoked by the metaphor but does not reorient its axiology totally since it is strongly motivated by the negative experiences described above.

\subsection{The sexual act is an INward movement}

In most cases this orientational metaphor is elaborated in Spanish by expressions axiologically associated with positive values, e.g. envainar (in English 'to sheathe') or meter la flauta en el estuche (in English 'put the flute in a case'). The positive axiological load conventionally attributed to the IN orientation is additionally reinforced by the positive experiences evoked by the non-erotic connotations of these lexical units. When we put a weapon, such as a knife or sword, into a sheath or a flute into a case, we protect these objects and prevent them from the impact of external factors. The insertion of the phallus to the vagina during the act of copulation is based in this case on the positive axiology associated with the IN(to) orientation and on the positive experiences of protection and safety.

Nevertheless, the axiology of the metaphor in question is not always positive in such a straightforward way since it is also linguistically realized by expressions such as hincar, meter un clavo or dar por donde amargan los pepinos. The first two refer to the act of sexual penetration in terms of the action of hammering a nail, which is evoked by the basic meanings of these lexical items registered in DRAE. The metaphorical projections emerging from them are based on the imagery of the phallus receiving the attributes typical of a sharp nail, introduced into the vagina by force and in a violent way (it is not put in but rather stuck IN). The projection of sexual intercourse stemming from these expressions is grounded in a negative experience of violence, whose victim is 
the woman participating in the intercourse. It is worth emphasizing that from the perspective of the agent of the actions (who is conceptualized in terms of a torturer) the action of hammering the nail is associated with reaching the GOAL. It reinforces a positive axiological load which is weakened by the negative experience of violence.

An interesting case from the axiological point of view is the expression dar por donde amargan los pepinos, which literally means 'to give through the place where the cucumbers get bitter'. Although this translation sounds exotic and artificial in English, it is necessary to understand the metaphor elaborated by this phrasal verb in order to be able to reconstruct its axiology.

First of all, there are different expressions in Spanish which designate the action of inserting an object INTO something. One of the most frequently used of them is the verb meter, whose basic meaning is 'to put, to introduce something inside'. Nevertheless, it is also possible to use in this context the expression dar por which, as can be seen in the previously proposed translation, literally means 'to give through'. This clarification is fairly relevant axiologically, since the penetration conceptualized in terms of putting the flute in a case or hammering a nail is associated with completely different values than the penetration metaphorically projected by means of the action of giving. If we give something, it usually shows our kindness and generosity towards somebody. From this perspective, the penetration evoked by the expression dar por has positive connotations. It contrasts with the violent image of penetration projected by the previously quoted expressions, hincar or meter un clavo.

In order to fully reconstruct the axiology connected with the expression dar por donde amargan los pepinos, it needs to be added that in an erotic context it refers to the act of sodomy (Rodríguez González, 2011, p. 310). A place 'where the cucumbers embitter' (donde amargan los pepinos) is one of numerous Spanish lexical items referring to the anus. The anus is located at the BACK of the body. Its negative axiology associated with the BACK orientation is additionally reinforced by the image of embittered cucumbers. If the cucumbers embitter, they are probably experiencing some kind of decomposition or degradation and, as a result, they lose their canonical form (Krzeszowski, 1993, p. 311). In other words, the expression in question evokes one of the experiences considered by Krzeszowski as those which reinforce the negative axiological load attributed to the PART in the PART-WHOLE preconceptual image schema (Krzeszowski, 1993, p. 311).

In summary, the expression dar por donde amargan los pepinos elaborates the metaphor of the sexual act based on the axiological struggle. On one hand, the act of penetration itself, which consists in introducing the phallus into the body of the woman, is positively charged. It is motivated by the axiology associated conventionally with the IN orientation in the BODY-AS-A-CONTAINER variant of the CONTAINER schema.

This positive axiological load is reinforced by the positive semantical connotations of the expression dar por. On the other hand, taking into account that the penetration denoted by the lexical unit in question is carried out through the anus, the sexual act is negatively charged. It is motivated by the negative axiology conventionally attributed to the BACK orientation and by the image of the embittering cucumber, which reinforces the negative axiology of the PART in the PART-WHOLE schema.

\subsection{The sexual act is an OUTward movement}

The axiology associated with this metaphor is systematic and stable, which contradicts the observations made by Krzeszowki referring to the changeable character of values ascribed to the OUT orientation (see subsection 2.1.3). Two selected examples of expressions which elaborate the metaphor THE SEXUAL ACT IS AN OUTWARD MOVEMENT will now be analyzed.

The first expression is the idiom descargar el biberón, whose literal meaning in a non-erotic context is 'to empty the bottle with teat'. The metaphor of heterosexual intercourse evoked by this expression is based on the series of visual analogies between the action of emptying a baby's bottle of milk through the hole in the teat and ejaculation. In both cases, there is an allusion to a white liquid (milk and sperm) getting OUT of the CONTAINER (a bottle or, projected in 
terms of this object, a male sexual organ) inside of which it was to be found before. In order to attribute a proper axiological load to the orientational metaphor, several factors need to be taken into account.

Firstly, it is no coincidence that Spanish speakers use the verb descargar, which literally means 'to remove a load or weight, to get rid of it' (DRAE), in this context. It is worth asking why they do not use the verb vaciar, since, semantically speaking, it is directly connected with the action of leaving something empty (DRAE). The use of descargar is probably due to the fact that it would change the projection of the sexual act evoked by the expression in question. It seems that the semantics of the verb descargar have a significant influence on the axiology of the whole expression. The entails not only an OUTwards movement (getting out of a CONTAINER), but also the fact that the load which was inside the CONTAINER was excessive (the Spanish term carga semantically refers to an object which presses heavily and may be perceived as a burden). Male semen, which receives the attributes of milk, is therefore considered to be an overload or excessive burden, which is something that has a negative impact on human life and from which a human being can not break free. The act of expelling a substance of such properties out of the body is to be associated with something positive: the male organism is "freed" of the "overload".

The second expression to be analyzed in the context of the metaphor THE SEXUAL ACT IS AN OUTWARD MOVEMENT is soltar las cascarrias, which can be translated as 'shake off the dirt from the bottom of your trousers / dress' (DRAE). Similar to the expression descargar el biberón, this idiom evokes the image of ejaculation in the context of heterosexual intercourse. In this case, the sperm is conceptualized in terms of dirt which is let OUT of the male body. The OUTward movement yet again is associated with a positive axiology since, thanks to this activity, the man is "cleansed". The positive axiological load connected with the OUT orientation is reinforced by the positive experience of freedom, to which the semantics of the verb soltar alludes.

\subsection{The sexual act is a movement from/at the BACK}

Spanish sex-related orientational metaphors are not always connected with a straightforwardly directed movement. There is, for instance, a group of expressions which evoke the BACK orientation by referring to the BACK part of the human body.

One of the most interesting lexical items from the axiological point of view is the verb rabear, whose basic meaning is 'to wag a tail'. Rabo ('tail') is one of many Spanish terms which allude to the penis. Its use in the erotic context involves the spatial reorientation of those elements that are of interest. The human phallus, positioned in the FRONT part of the body, receives the attributes of the animal tail positioned in the BACK part of the body. The movements of the penis executed in the FRONT during the intercourse are conceptualized in terms of the movements of the tail executed from/at the BACK. As mentioned before, BACK is conventionally negatively loaded (see 2.1.2).

The negative axiology associated with the human penis and with the sexual act denoted by the verb rabear is directly connected with the values ascribed to the BACK orientation. It is reinforced by the "homo-animal opposition", described by Agnieszka Libura (2003, p. 121). ${ }^{8}$ According to Libura, "the human body is 'normal' so non-human parts of the, body - wings, tails, horns - are axiologically differently charged" (Libura, 2003, p. 121). ${ }^{9}$ From the anthropocentric perspective, everything which is not originally human should be considered inferior (see 4.1). Due to this fact, the perception of the human penis in terms of a tail, and of heterosexual intercourse in terms of wagging the tail, lowers the axiological status of male genitalia and of the act of copulation itself. The axiology evoked by this expression is not, however, straightforwardly negative. It should be remembered that animals frequently express joy and contentment by wagging their tails. Taking

\footnotetext{
${ }^{8}$ In original: "opozycja homo - animal". The translation is mine.

${ }^{9}$ In original: "Ciało ludzkie jest $<$ normalne $>$, dlatego nie-ludzkie części ciała — skrzydła, ogony, rogi — są w różny sposób nacechowane." The translation is mine.
} 
into account this extralinguistic experience, the action of wagging the tail is to be associated with a positive axiology.

The case of the verb rabear proves, contrary to Krzeszowski's statements, that the BACK orientation is not always negatively charged.

\section{Conclusions}

The results of the research on sex-related metaphors in Spanish presented above show that the PLUS-MINUS parameter is indispensable in order to reconstruct as completely as possible the picture of particular elements of reality grounded in language.

As has been demonstrated, in many cases the observations made by Krzeszowski concerning the correlations between the orientation and the axiology are universal. To give an example, a lot of linguistic elaborations of sex-related orientational metaphors in Spanish are positively loaded in the context of the UP orientation and negatively loaded in the context of the DOWN orientation. However, the conventional axiology attributed to a specific orientation is sometimes reversed. There are cases of positively charged expressions, e.g. emplitrarse, encamarse or revolcarse, which evoke the DOWN orientation, normally associated with the minus pole of the UP-DOWN schemata (see 4.2).

The analysis carried out within this paper enables the verification of the universality of $\mathrm{Kr}$ zeszowski's thesis that the values attributed to the IN(to)-OUT orientation are not stable. The study of Spanish metaphors associated with the erotic sphere confirms that as far as the IN(TO) orientation is concerned, the axiology associated with the IN orientation is in fact complex and sometimes (e.g. dar por donde amargan los pepinos) leads to different axiological struggles (see subsections $4.3,4.4)$. The OUT orientation, by contrast, is axiologically stable and is always positively loaded in a sexual context. This shows that Krzeszowski's claims cannot be considered a general principle.

Other important statements which were presented in Krzeszowski's 1993 work, and which are referred to in this paper, place an emphasis on the correlations between different image schemata. He argues, for example, that the IN(to)-OUT schema overlaps with the CONTAINER and LINK schemas (see 2.1.3, 2.1.4). This paper has revealed some correlations which were not described by Krzeszowski and should be considered unconventional. For instance, there was a case when the DOWN orientation overlapped with the $\mathrm{IN}(\mathrm{to})$ one (e.g. enterrar la sardina), which contributed to the reorientation of positive values attributed conventionally to the $\mathrm{IN}$ (to) orientation.

During the reconstruction of an expression's axiology, it is worth remembering that the orientation is only one of many determinants of the values ascribed to particular metaphors. Researchers who conduct investigations into this matter should also take into account all of the denotations and connotations of the linguistic elaborations of these metaphors and other factors like, for example, the human attitude towards the surrounding world (see 4.1, 4.2, 4.5). The results of axiological analysis conducted in this manner may reveal details of special importance for contrastive studies or translation practice. Some examples of these findings will be presented in the following section.

\section{The PLUS-MINUS parameter in contrastive studies}

Taking into account the final conclusions drawn from the study, following section of the paper will try to determine whether the type of orientation is associated with a particular axiological load universally, or whether the axiology connected with the spatial orientation may vary within two different language systems. In this regard, it is interesting to search for some Polish equivalents of the selected sex-related orientational metaphors in Spanish.

To illustrate the problem, the metaphor THE SEXUAL ACT IS AN UPWARD MOVEMENT will be used as an example. In Spanish it is evoked, among others, by means of the expressions formed on the basis of the verb montar (see subsection 4.1). As has been demonstrated, the 
The PLUS-MINUS axiological parameter in selected sex-related orientational metaphors in Spanish...

axiology emerging from the metaphors elaborated by these lexical items is generally consistent with the axiology stemming from the UP-DOWN schema, where UP is conventionally associated with thr plus pole and DOWN with the minus pole. Nevertheless, the specific metaphorical projection of sexual intercourse itself depends on concrete expressions. There are cases in which it is the man who "mounts a woman" in erotic situations and moves UPwards in order to do that. After climbing UP, the man places the woman DOWN and gets on top of her as if he was a horse rider who has mounted a mare. The positive image of a male horse-rider, who climbs UP and is UP during the sexual act, contrasts with the negative image of the dominated woman, who was moved DOWNwards from her initial upper position (e.g. montar una mujer, montarla). However, it has been shown that the verb montar may sometimes be associated with a female grammatical subject. This has an influence on the axiology of the orientational metaphor in question. This is the case of the phrasal verb montar en barra, the analysis of which evokes the image of a woman who is UP and plays a crucial role in the sexual act. In this case, the values attributed to her are highly positive while a male lover, by contrast, is negatively loaded (see section 4.1)

In the dictionary of Polish sex-related terms, Stownik seksualizmów polskich by Jacek Lewinson (1999), it is possible to find some lexical items which evoke the same metaphor as their Spanish counterparts, which is to say, THE SEXUAL ACT IS AN UPWARD MOVEMENT (see Table 2).

Table 2: Selected Polish realizations of the metaphor SEXUAL ACT IS THE UPWARD MOVEMENT and their translations into English

\begin{tabular}{|c|c|}
\hline Polish expressions & Literal translations to English \\
\hline 1. Dosiadać & 1. To mount \\
\hline a. jak kotke & a. like a she-cat \\
\hline b. konia & b. a horse \\
\hline 2. Wsiadać na [mężczyznę] & 2. To get on $[$ a man $]$ \\
\hline 3. Wchodzić na kukułke & 3. To climb a cuckoo \\
\hline 4. Wskoczyć na chuja & 4. To hop on a cock \\
\hline
\end{tabular}

The expressions marked with number 1 , formed on the basis of the verb dosiadać, seem to be fairly similar to the Spanish expressions formed on the basis of the verb montar. As a matter of fact, the translation of both verbs into English is identical (to mount). Nevertheless, it is worth investigating whether the specific metaphorical projection, and consequently the axiology emerging from the analysis of these lexical items, is also the same in both languages.

In the case of the expression dosiadać jak kotke, it is the male lover who is UP and mounts the woman as if she was a cat. In this relation, the woman is obviously DOWN. The axiological and ontological status of the female lover is therefore very low: she receives the attributes of an animal and she is positioned DOWN in relation to her sexual partner. In other words, the anthropocentric perspective (which involves the attribution of negative values to all of the nonhuman elements of reality) reinforces the negative axiological load of the woman associated with the DOWN orientation (related to the minus pole of the UP-DOWN schema). This vision is consistent with the projection stemming from the study of the Spanish expressions montar una mujer or montarla. The only difference is that in the case of the Spanish lexical items, the female lover is conceptualized in terms of a mare and not a she-cat. Nevertheless, the negative axiology associated with the woman has the same motivation in both languages (the DOWN orientation and the anthropocentric perspective).

The axiology ascribed to the man is more ambiguous in this context. Although the English translations of the cited Spanish and Polish expressions are almost the same, the projection of the male lover and his axiological load is different in both languages. Both in Spanish and in Polish it is the man who mounts the woman. As demonstrated in section 4.1, the Spanish verb 
montar alludes to the UPWARD movement made by the man, as a consequence of which the man is UP during the intercourse. The UP orientation associated conventionally with the plus pole of the UP-DOWN schema contributes to the positive values attributed to the man in the sexual context. The Polish verb dosiadać has, however, different connotations, which affect the axiology of the male lover. One of its basic meanings is "to sit DOWN on a horse's back in order to ride it" (Lewinson, 1999, p. 40). ${ }^{10}$ This lexicographical definition suggests that in Polish a man involved in the sexual act has to make a DOWNward movement in order to be positioned UP during the intercourse. Of course, the action of getting on the horse by somebody always involves an UPWARD movement and, according to other lexicographical definitions of the verb dosiadać registered in Polish general dictionaries, it entails this meaning as well. ${ }^{11}$ Nevertheless, at the same time it evokes a DOWNward movement. This means that the positive axiological load of the man associated with the UP orientation is weakened by the negative axiology conventionally associated with the DOWN orientation. In other words, the axiology attributed to the male lover emerging from the analysis of the Polish expression dosiadać jak kotke is not as straightforward as in the case of its apparent Spanish counterpart montar una mujer. It also proves that the conventionally bi-polar UP and DOWN orientations sometimes do overlap, which leads to axiological struggles.

As far as the Polish expressions formed on the basis of the verb dosiadać are concerned, it is worth observing that while in Spanish it tends to be the man who "mounts a woman" in erotic situations (see section 4.1), in Polish it is more frequently the woman. The action of mounting a horse evoked, among others, by the phrasal verb dosiadać konia (see Table 2) always involves a female grammatical subject in Polish. This means that Polish sex-related orientational metaphors connected with the UP-DOWN orientation normally entail the projection of the woman UP and the man, who receives the animal attributes of a horse, DOWN. The female lover is therefore more frequently associated with a positive axiological load in Polish than in Spanish in the context of the UP-DOWN schema. The male lover, by contrast, is more frequently associated with a positive axiological load in Spanish in the context of the same orientational schema. In Polish, he is normally negatively charged. This is illustrated, among others, by means of the expressions 2,3 and 4 included in Table 2. In Polish, it is the woman who 'gets on a man', 'climbs a cuckoo' or, in more vulgar register, 'hops on a cock'. In each case, a female lover is positioning herself UP and the man DOWN. Furthermore, the low axiological status of the man resulting from the DOWN orientation ascribed to him is in some cases weakened even more by his projection in terms of non-human elements of the world (e.g. 'cuckoo').

All of these conclusions reveal that the insertion of the PLUS-MINUS parameter to interlingual contrastive studies presents great potential. It can be observed that the orientational metaphors in two different language systems may have different axiological backgrounds. This is extremely important for translation studies and translation practice since, as has been demonstrated, some interlingual equivalents of sex-related expressions are only apparently similar and often entail totally different metaphorical projections associated with opposite axiological poles.

\section{References}

Diccionario de la lengua española [DRAE]. (2001) (22 ed.). Madrid: Espasa. Retrieved 25 July 2016, from http://www.rae.es/

Johnson, M. (1987). The body in the mind. Chicago, IL: University of Chicago Press.

Johnson, M. (2007). The meaning of the body: Aesthetics of human understanding. Chicago, IL: University of Chicago Press.

Johnson, M., \& Lakoff, G. (1999). Philosophy in the flesh: The embodied mind and its challenge to Western thought. New York: Basic Books.

Krzeszowski, T. P. (1993). The axiological parameter in preconceptual image schemata. In R. Geiger \& B. Rudzka-Ostyn (Eds.), Conceptualizations and mental processing in language (pp. 307-329). Berlin:

\footnotetext{
${ }^{10}$ In original: "usiąść na grzbiecie zwierzęcia w celu jazdy wierzchem". The translation is mine.

${ }^{11}$ Cf., for example, Stownik języka polskiego PWN (n.d.).
} 
Mouton de Gruyter. https://doi.org/10.1515/9783110857108.307

Lakoff, G. (1987). Women, fire and dangerous things: What categories reveal about the mind. Chicago, IL: University of Chicago Press.

Lakoff, G., \& Johnson, M. (1980). Metaphors we live by. Chicago, IL: University of Chicago Press.

Lewinson, J. (1999). Słownik seksualizmów polskich. Warszawa: Książka i Wiedza.

Libura, A. (2003). Wartościowanie związane z wybranymi przedpojęciowymi schematami wyobrażeniowymi na przykładzie nazw części ciała ludzi i zwierząt. In A. Dąbrowska (Ed.), Język a Kultura (Vol. 15, Opozycja homo-animal w jezyku i kulturze, pp. 117-127). Wrocław: Wydawnictwo Uniwersytetu Wrocławskiego

Popek-Bernat, K. (2015). Valoración en las metáforas lingüísticas: proyecciones del amante codificadas en el léxico erótico español peninsular. Itinerarios, 22, 101-112.

Rodríguez González, F. (2011). Diccionario del sexo y el erotismo. Madrid: Alianza Ed.

Stownik języka polskiego PWN. (n.d.). Retrieved 30 July 2016, from http://sjp.pwn.pl/

Tokarski, R. (1991). Wartościowanie człowieka w metaforach językowych. Pamiętnik Literacki, 82(1), $144-157$.

\section{Acknowledgment}

This work was financed by the Polish Ministry of Science and Higher Education.

The author declares that she has no competing interests.

This is an Open Access article distributed under the terms of the Creative Commons Attribution 3.0 PL License (http://creativecommons.org/licenses/by/3.0/pl/), which permits redistribution, commercial and noncommercial, provided that the article is properly cited.

(C) The Author 2017

Publisher: Institute of Slavic Studies, Polish Academy of Sciences, University of Silesia \& The Slavic Foundation 